\title{
Compound motor action potentials in transient and persistent phrenic nerve injury - metanalysis.
}

\author{
Marcin Kuniewicz ${ }^{1}$ and Marcin Kowalski² \\ ${ }^{1}$ Jagiellonian University in Kraków Medical College \\ ${ }^{2}$ Commonwealth University School of Medicine
}

March 1, 2023

\begin{abstract}
Background: The right phrenic nerve is vulnerable to injury (rPNI) during cryoballoon ablation (CBA) isolation of the right pulmonary veins. The complication can be transient or persistent. The reported incidence of rPNI fluctuates from $4.73 \%$ to $24.7 \%$ depending on changes over time, CBA-generation, and selected protective methods. Methods: Through September 2019, a database search was performed on MEDLINE, EMBASE, and Cochrane Database. In the selected articles, the references were also extensively searched. The study provides a comprehensive meta-analysis of the overall prevalence of rPNI, assesses the transient to persistent PNI-ratio, the outcome of using compound motor action potentials (CMAP), and estimated average time to nerve recovery. Results: From 2008 to 2019, 10,341 records from 48 trials were included. Out of 783 eighty- PNI (7.7\%), $589(5.7 \%)$ were transient, and $194(1.9 \%)$ were persistent. CMAP caused a significant reduction in the risk of persistent PNI from $2.3 \%$ to $1.1 \%$ ( $\mathrm{p}=0.05$; odds ratio $[\mathrm{OR}] 2.13$ ) in all CBA groups. The mean time to rPNI recovery extended beyond the hospital discharge was significantly shorter in CMAP group at three months on average versus non CMAP at six months ( $\mathrm{p}=$ 0.012). CMAP (in contrast to non-CMAP procedures) detects PNI earlier from 4 to 16 sec (p $<0.05$; I2 $=74.53 \%$ ) and 3 to $9^{\mathrm{o}}$ $(\mathrm{p}<0.05 ; \mathrm{I} 2=97.24 \%)$ earlier. Conclusions: rPNI extending beyond hospitalization is a relatively rare complication. CMAP use causes a significant decrease in the risk of prolonged injury and shortens the time to recovery
\end{abstract}

Title: Compound motor action potentials in transient and persistent phrenic nerve injury - metanalysis.

Authors: Marcin Kuniewicz MD, PhD (1,2), Marcin Kowalski (3)

${ }^{1}$ Department of Anatomy, Jagiellonian University Medical College, Cracow, Poland

${ }^{2}$ Department of Electrocardiology, Institute of Cardiology, Jagiellonian University Medical College, Poland

${ }^{3}$ Department of Medicine, Division of Cardiac Electrophysiology, Staten Island University Hospital, Staten Island, New York

\section{Address for correspondence:}

Marcin Kuniewicz, MD, $\mathrm{PhD}$,

Department of Anatomy Jagiellonian University Medical College

Kopernika 12, 31-034 Kraków. Poland

Tel./fax. (0048)124229511

E-mail: kuniewiczm@gmail.com

ORCID: 0000-0002-0029-5553

\section{Conflict of interest:}


All authors have reported that they have no relationships relevant to the contents of this paper to disclose.

Contributions: M. K.: the concept and design, data collection, statistical analysis, writing the manuscript. M.K.: the inspiration, concept and design, revising article critically for important intellectual content, final approval of the version to be submitted,

Funding: No funding was received.

\section{Disclosures: none}

Other declarations: not applicable

\section{Abstract}

Background: The right phrenic nerve is vulnerable to injury (rPNI) during cryoballoon ablation (CBA) isolation of the right pulmonary veins. The complication can be transient or persistent. The reported incidence of rPNI fluctuates from $4.73 \%$ to $24.7 \%$ depending on changes over time, CBA generation, and selected protective methods.

Methods: Through September 2019, a database search was performed on MEDLINE, EMBASE, and Cochrane Database. In the selected articles, the references were also extensively searched. The study provides a comprehensive meta-analysis of the overall prevalence of rPNI, assesses the transient to persistent PNI ratio, the outcome of using compound motor action potentials (CMAP), and estimated average time to nerve recovery.

Results: From 2008 to 2019, 10,341 records from 48 trials were included. Out of 783 eighty- PNI (7.7\%), 589 $(5.7 \%)$ were transient, and $194(1.9 \%)$ were persistent. CMAP caused a significant reduction in the risk of persistent PNI from $2.3 \%$ to $1.1 \%$ ( $\mathrm{p}=0.05$; odds ratio $[\mathrm{OR}] 2.13$ ) in all CBA groups. The mean time to rPNI recovery extended beyond the hospital discharge was significantly shorter in CMAP group at three months on average versus non CMAP at six months $(\mathrm{p}=0.012)$. CMAP (in contrast to non-CMAP procedures) detects PNI earlier from 4 to $16 \sec \left(\mathrm{p}<0.05 ; \mathrm{I}_{2}=74.53 \%\right)$ and 3 to $9^{\mathrm{O}}\left(\mathrm{p}<0.05 ; \mathrm{I}_{2}=97.24 \%\right)$ earlier.

Conclusions: rPNI extending beyond hospitalization is a relatively rare complication. CMAP use causes a significant decrease in the risk of prolonged injury and shortens the time to recovery.

\section{Introduction}

Since 2006, the cryoballoon ablation (CBA) technique has revolutionized the treatment of paroxysmal atrial fibrillation and has become the gold standard treatment method since 2012. The main reason behind its efficacy is its simplifying pulmonary vein (PV) isolation, making it a highly standardized and reproducible procedure [1-3]. Nevertheless, CBA is associated with a significant risk of right phrenic nerve injury (rPNI) because of the proximity between the right phrenic nerves and the right-sided PVs during balloonbased ablations [4]. PNI can be transient or persistent, and that feature depends on the time to recovery. Transient phrenic nerve paralysis/injury (TPNI) is defined either as completely resolved before the end of the procedure [5,6], lasting less than 24 hours [7], or until discharge as demonstrated by chest fluoroscopy [8]. Any longer period of diaphragmatic paralysis is defined as persistent or sustained phrenic nerve injury (PPNI). In a systematic review, the reported incidences of transient and persistent PNI resulting from ablation with the first-generation CB were $6.48 \%$ and $4.73 \%$, respectively [9]. The risk of PNI associated with the second-generation CB is even higher with a reported incidence of transient and persistent PNI being $16.0 \%-24.7 \%$ and $5.4 \%-7.0 \%$, respectively [10-13]. The anatomical relationship of the relevant structures makes the risk unavoidable; however, various techniques have been implemented throughout the last decade for preventing prolonged rPNI [14]. The most used technique involves the use of compound motor action potentials (CMAP). The first record of CMAP was published in 2011 by Franceschi [15]; later, two studies, including multiple patients, were published in 2014 with a significant PPNI reduction [16,17].

In this article, we aimed to perform a systematic review of PNI based on all cryoballoon generations from the last 12 years by conducting a meta-analysis to assess the efficacy of diaphragmatic stimulation and CMAP 
use for PNI protection. Intra-operative physical conditions both with and without right dome diaphragmatic stimulation and time to recovery data were collected.

\section{Methods}

Through September 2019, literature searches were performed using the MEDLINE, EMBASE, and Cochrane databases to identify eligible articles. This review was performed according to the Preferred Reporting Items for Systematic Reviews and meta-analysis guidelines (PRISMA) guidelines [18]. The exhaustive search strategy used for the databases is presented in Table 1. No date limits or language restrictions were applied. The references in the included articles were also extensively searched. The risk of bias and quality assessment scores were both performed based on the Newcastle-Ottawa Scale (NOS) to further evaluate the quality of the observational studies, and NOS [?] 7 was regarded as a good quality score [19].

\section{Study Selection}

Studies that were eligible for meta-analysis using the keywords/phrases, right phrenic nerve protection, right PNI, and CMAP were included under certain conditions: (1) reported clear, data that was easy to extract for further analysis, (2) studies were retrospective and observational in nature. The exclusion criteria included case studies, case reports, conference abstracts, and letters to the editor, incomplete and unclear data, studies on animals, or those not related to CBA procedures. All studies were independently evaluated for inclusion by two investigators. Any disparities arising during the assessment were resolved by a consensus among all the reviewers after consulting with the authors of the original study if possible.

\section{Data extraction and quality assessment}

All publication pieces of data were extracted: (1) publication information (the first author's name, publication year), (2) cohort demographics (sample size, gender constituent ratio, mean age, comorbidity), (3) atrial fibrillation (AF) duration, (4) body mass index (BMI), (5) echocardiographic parameters (left ventricular ejection fraction (LVEF), (6) left atrial dimension (LAD), (7) procedural data, including cryoballoon generation (first generation: CB-1, second generation (advanced): CB-2, third generation (short tip): CB-ST), balloon dimension (23 or $28 \mathrm{~mm}$ ), balloon location (right superior pulmonary vein right [RSPV] or inferior pulmonary vein [RIPV]), time and nadir temperature to rPNI, diaphragmatic protection (fluoroscopy, palpation, stimulation, including cycle, strength of impulse, positioning of pacing electrode and CMAP), procedural and delayed complications of phrenic nerve palsy. Whenever the data of interest were incomplete, the investigators did not use the study in the meta-analysis. In some publications, only a selected group was used for analysis once the same data were found in other publications (example Aryana 2014 [34], 2015 [6], 2016 [44]; 2014: CB-1/CB-2 2014: only CB-1 taken from a database; 2015: CB-2 2012-2015.02 CB-2 all taken from database; 2016: CB-2/CB-ST from 2015.3: all data taken from database).

\section{Statistical analysis}

Statistical analyses were performed using the Statistica (TIBCO v.13.3) software. Continuous variables are expressed as mean \pm standard deviation (SD) or median range as appropriate. Confidence intervals $(95 \%$ CI) for individual groups and the whole group were measured. For a subset of studies with analyzable and comparable data, the results were synthesized quantitatively by performing random-effects model metaanalyses to compute absolute net changes in continuous variables (for example, time to PNI or temperature to PNI) and pooled OR for binary variables (for example, PNI with CMAP and no phrenic nerve injury). All pooled estimates were displayed with a $95 \%$ CI. For PNI resolution the Wilcoxon Peto's log-rank test was used because higher sensitivity at early survival times than late ones. The existence of heterogeneity among effect sizes of individual studies was assessed using an I2 of higher than $50 \%$ with p value of $<0.1, Q$ test, and the $T^{2}$ index with a value of [?] 95\%, indicating medium-to-high heterogeneity. A funnel plot and Begg and Mazumdar's test were used to investigate publication bias for the primary clinical outcome.

\section{Results}

\section{Eligible studies}


For the most precise study selection, each database was scanned through combination of two key words: (1) cryoballoon ablation ANDphrenic nerve injury and cryoballoon ablation ANDcompound motor potential action OR (2) CMAP . Initially, 301 potentially relevant articles were identified according to the adopted search strategy. As illustrated in the flow diagram (Fig. 1), the first review excluded 216 papers based on screening the titles and abstracts, and an additional 21 articles were excluded after a detailed evaluation in addition to 64 articles thoroughly enrolled with timeline and centers origin with intermeshing of records. Finally, 48 eligible observational controlled and noncontrolled trials that fulfilled all inclusion criteria for PNI registry [2,5-17,20-60] Figure 1. For metanalysis of PN protection, location of PNI, and time to resolution of PNI, different criteria ware used; thus, a significantly less papers met the final criteria, and each part of the analysis was estimated separately. Nevertheless, the method and equipment of CBA is unified so that they can be analyzed together and in dependent subgroups.

The studies included in this meta-analysis were published between September 2008 [21] and May 2019 [60]. Two randomized controlled trials met the inclusion criteria [54,57]. The reasons for final exclusion were lack of essential clinical outcome data, repeated records in databases, review articles, duplicated studies, and non-controlled trials. As to the quality of those included studies forty-eight full-text studies were allocated a NOS score of [?] 7 [19].

\section{Baseline characteristics of included study}

All enrolled clinical studies were published form 2008 [20] to 2019 [60]. The first enrollment of CBA: CB-1 was found in 2007 [61]; however, records from this study were used later in 2008 in a larger observational registry [22]. The total number of patients in this meta-analysis reached 10,341 with 4164 patients undergoing first generation CBA: CB-1 (23 mm [1164 patients] and 28mm [3328 patients]), 6075 with second generation CBA: CB-2 (23 mm [192 patients] and $28 \mathrm{~mm}$ [5765 patients]) and finally 102 patients who had an ablation with the third generation CB-ST procedure, $28 \mathrm{~mm}$. Discrepancies in the number of $2328 \mathrm{~mm}$ and number of procedures could have resulted from the use of two types of diameters in one procedure.

All trials $(\mathrm{n}=48)$ for PNI with relevant baseline information included patients comparable on mean age, gender ratio, body mass index (BMI), atrial fibrillation (AF) duration, comorbidities, left ventricular ejection fraction (LVEF), and left atrium size between the CB generations (Table 1). Each study describes the method of phrenic nerve control and protection (supplemental publication material Table 1), number of PNI $(\mathrm{n}=48)$, and time to recovery $(\mathrm{n}=37)$, if not in days, at least at check-up periods. Intraoperative data was found in 13 studies $[8,15,17,23,29,30,36,38,42,47,48,52,62]$ providing a detailed time to PNI, only eight $[15,30,38,42,47,48,52,62]$ studies delivered information about nadir disruption of temperature to PNI while only five $[15,38,42,48,62]$ detailed time, temperature, and balloon location of the right superior pulmonary vein/right inferior pulmonary vein (RSPV/RIPV) In 20 studies, we found information about diaphragmatic stimulation, 17 described the strength of power to stimulation, 30 studies described the time of freezing as shown in the supplemental publication material.

CMAP was used in 15 studies, four used immediate balloon deflation (IBD; one CMAP + IBD), 30 studies used fluoroscopy control with palpation, and two studies did not use any phrenic nerve protection [20,21]. Detailed information of data included in certain studies are shown in column 13, Table 1. Except for statistical significance of hypertension diagnosis between the CMAP and non-CMAP group, almost all the other demographic characteristics (age, gender, AF duration) and echocardiographic data (left atrium diameter [LAD], left LVEF) were comparable between these two groups. Statistical analyses of the baseline demographic and echocardiographic data are presented in Table 2. The study did not compare the 6-month or 1-year efficacy because of different balloon generations, sizes, and selected techniques. The average success rate ranged from $59.7 \%$ in CB-1 [40] to $90.83 \%$ in CB-2 [35] with a mean of $75.82 \%$ overall.

\section{Transient versus persistent phrenic nerve injury (primary outcome).}

From 10,341 records, information about 783 PNI (7.7\%) was found; 589 (5.7\%) were transient, while 194 $(1.9 \%)$ were persistent. In the CB-1 generation $(\mathrm{n}=4164$ records with $4492 \mathrm{CB}-1$ balloons), PNI was found in 302 cases $(7.2 \%)$, in the CB-2 generation $(\mathrm{n}=5957)$ was found in 466 cases $(7.8 \%)$, and in the CB-ST (n 
$=102), 15(1.96 \%)$ were found. After obtaining the results from studies reporting relevant detailed data, we observed that the number of PNI in the CMAP and non-CMAP groups was similar and did show statistical difference $(\mathrm{p}=0.56$, odds ratio [OR]: 0.96; $95 \%$ CI [0.82-1.11]). The transient subgroup was seen significantly more often in the CMAP group, while the PPNI was present more often without CMAP use (Table 3).

Dividing PNI into transient and persistent PNI in CMAP and non-CMAP group showed statistical significance for all variants except transient PNI in the CB-2 group. A statistical difference was found in almost all CBA generations with the highest incidence in persistent PNI in CB-1 (OR 3.4) and CB-2 (OR: 3.4 and 1.99, respectively). The inverse situation was found in transient PNI in the CB-1 group (OR: 0.47). Combined data from different CBA generations with and without CMAP use are presented in the Forrest plot in figure $2 \mathrm{~A}$. The funnel plot of the selected studies for the analysis shows the risk of bias in figure $2 \mathrm{~B}$. The only insignificance was noticed between TPNI in the CB-2 generation (CMAP/nonCMAP) ( $\mathrm{p}=0.75$; OR: 1.03). For this record, a Kaplan Meier's log- rank test was preformed and yielded a value of $\mathrm{p}=0.77$.

By obtaining the results from studies reporting relevant, detailed, intra-operative data regarding PNI, including time to PNI $(\mathrm{n}=243)$ and temperature to PNI $(\mathrm{n}=150)$, a significant difference between CMAP and non-CMAP groups was noticed. The mean difference for time to PNI was significant for CMAP and non-CMAP groups. The shortest time to PNI was found in the CMAP CB-1 and CB-2 groups (both 137 s). The longest time to PNI was observed in non-CMAP groups reaching 153 and $141 \mathrm{~s}$ for CB-1 and CB-2, respectively. The mean difference nadir temperature to PNI was lowest for $\mathrm{CB} 1\left(-59^{\circ} \mathrm{C}\right.$ at which the CMAP value could not be dispersed), for CB-2 non-CMAP and CMAP (-53 and $-50{ }^{\circ} \mathrm{C}$ ), which achieved statistical significance. The summarized graphs with heterogeneity values are shown in figure 3 .

\section{The location of the PNI}

The number of instances of PNI from the records reached $n=783$ (studies: 48) while the precise location as to right superior or inferior phrenic nerve was found in $\mathrm{n}=627$ (studies: 40). It was not surprising that most PNI were most frequently found in RSPV. Five-hundred eighteen PNI (82.6\%) occurred in RSPV and $109(17.4 \%)$ in RIPV ( $\mathrm{p}<0.005)$. In the CMAP/no-CMAP group, 206 were found in RSPV (77.4\%), 60 in RIPV (23.6\%), 312 in RSPV (86.4\%), and 49 in RIPV (13.6\%) based on results from the chi-square test (p $=0.003)$ as shown in figure 4 . It was impossible to collect precise data concerning the transition of transient PNI to persistent PNI combined with vein location in selected studies.

\section{Time to recovery PPNI (secondary outcome)}

From various definitions of persistent phrenic nerve injury (beyond procedure/discharge), we established the definition as impairment of diagrammatic stimulation beyond the time of hospitalization. In 37 studies with 194 cases it was decided that after recalculating those occurrences after the procedure but not after hospitalization to define that group as transient PNI. Eighty-one persistent PNI after CB-1 and 113 after CB-2 generation were noted. In the CB-1 group, almost half of the nerve injuries (40 PPNI; 49,4\%) were associated with $23 \mathrm{~mm}$, although the use of CB1-23 mm accounted for almost a quarter of the total first generation $(\mathrm{n}=1164 ; 25.9 \%)$. In CB-2, the use of $23 \mathrm{~mm}$ significantly decreased to $\mathrm{n}=192(3.3 \%)$ after which the incidence with $23 \mathrm{~mm}$ became statistically insignificant. In CB-2, CMAP usage became a marker. Seventy-three (64.6\%) PPNI occurred without the CMAP, and $40(35.4 \%)$ occurred with CMAP use (p < $0.05)$.

We investigated the time to recovery based on the registries. The information was found in 27 studies by observing 150 PPNI, 66 from CB-1 and 84 from CB-2. Precise data with time to resolution were collected from $138 \mathrm{PNI}$ and divided into persistent PNI-CMAP and persistent PNI non-CMAP protection groups. The median time to recovery in the persistent PNI with CMAP group was three months (standard deviation [SD] $3.45 ; 95 \%$ CI 1.9-4.1) while without CMAP protection, this time was prolonged to six months (SD 4.1; 95\%CI $5.2-6.8)$ with statical significance based on Wilcoxon Peto's log-rank test $(\mathrm{p}=0.012)$ as shown in Figure 5. Only 12 results were described as unresolved ranging over 24 months beyond the observation period. The longest time of observation of unresolved persistent PNI reach over 36 month [46]. Detailed information of PNI follow-up can be found in the supplemental publication material. 


\section{Discussion}

From the very beginning of the CBA procedure, PNI was associated with right-sided pulmonary vein isolation. No CBA registry in literature without PNI can be found, and every comparison or meta-analysis between RF ablation and cryo-registry shows a disadvantage in this field $[6,24,31,37,41,43,49,63,64]$. The reason for this issue is a combination of the right phrenic nerve course and cryo-energy dispersion delivered during the procedure [4,65]. Any assessment of distance between PVI ostium and PN may only alert for potential, upcoming complications [4]. Nevertheless, PNI complication is heterogeneous. From our perspective, TPNI (5.7\%), resolving until the end of the procedure is a mild complication resulting incomplete or short time vein isolation and up to the day of discharge, also requires an additional $\mathrm{X}$-ray. The serious problem occurs with PPNI (1.9\%) that extends beyond the hospital discharge. Most patients have no symptoms during rest, whereas physical activity induces symptoms, such as dyspnea [66,67]. The time for PNI resolution varies significantly. Most can take up to six months to resolve, and almost all are resolved by 12 months. Patients with PPNI need regular checkups and fluoroscopic or sonographic evaluation [64]. We conducted that the first-generation of CB (CB-1) $23 \mathrm{~mm}$ CB-1 (deeper seating), which increased the risk of PNI almost threefold [9]. In the second-generation CBA, a redesigned cooling area caused an increase in the incidence rate, reaching almost $20 \%$ overall in some trials $[2,10,33,37,57]$. Various anatomical predictors were proposed for preventing PNI [68]. The CMAP presented by Franceschi [15] can be called a game-changer by decreasing the amount of persistent PNI. After implementing this method, the PNI decreased significantly from 2.3 to $1.1 \%$. Monitoring diaphragmatic CMAP during phrenic nerve injury capture allows earlier detection of phrenic nerve dysfunction $[15,30,36]$. The mean difference in time to PNI between CMAP and the non-CMAP group was shorter, and the temperature was higher, thus causing a benign injury. Lower temperatures and longer applications caused an increase in the risk of PNI, which was also observed by other authors [48]. Analysis of cycle length of phrenic nerve stimulation with the impulse strength did not reveal any statistical favorites; however the Okishige et al. proved that the PNI manifested earlier with weaker power of stimulation [53].

Nevertheless, no technique eliminates the risk of PNI associated with CBA. From this record, long, persistent PNI lasting beyond the time of observation have been reported with and without CMAP $[34,35,47,48]$. Finally, the amount of PPNI with CMAP decreased and the median time to resolution was shortened from six to three months. This meta-analysis summarizes the findings that CMAP should be obligatorily implemented during each CBA.

\section{Referencess:}

1. Sorgente A, Chierchia GB, de Asmundis C, Capulzini L, Sarkozy A, Brugada P. Cryoballoon ablation of atrial fibrillation: state of the art 10 years after its invention. Recent Pat Cardiovasc Drug Discov. 2010 Nov;5(3):177-83. doi: 10.2174/157489010793351917. PMID: 20874670.

2. Packer DL, Kowal RC, Wheelan KR, Irwin JM, Champagne J, Guerra PG, Dubuc M, Reddy V, Nelson L, Holcomb RG, Lehmann JW, Ruskin JN; STOP AF Cryoablation Investigators. Cryoballoon ablation of pulmonary veins for paroxysmal atrial fibrillation: first results of the North American Arctic Front (STOP AF) pivotal trial. J Am Coll Cardiol. 2013 Apr 23;61(16):1713-23. doi: 10.1016/j.jacc.2012.11.064. Epub 2013 Mar 21. PMID: 23500312.

3. Calkins H, Kuck KH, Cappato R, Brugada J, Camm AJ, Chen SA, Crijns HJ, Damiano RJ Jr, Davies DW, DiMarco J, Edgerton J, Ellenbogen K, Ezekowitz MD, Haines DE, Haissaguerre M, Hindricks G, Iesaka Y, Jackman W, Jalife J, Jais P, Kalman J, Keane D, Kim YH, Kirchhof P, Klein G, Kottkamp H, Kumagai K, Lindsay BD, Mansour M, Marchlinski FE, McCarthy PM, Mont JL, Morady F, Nademanee K, Nakagawa H, Natale A, Nattel S, Packer DL, Pappone C, Prystowsky E, Raviele A, Reddy V, Ruskin JN, Shemin RJ, Tsao HM, Wilber D. 2012 HRS/EHRA/ECAS expert consensus statement on catheter and surgical ablation of atrial fibrillation: recommendations for patient selection, procedural techniques, patient management and follow-up, definitions, endpoints, and research trial design. J Interv Card Electrophysiol. 2012 Mar;33(2):171-257. doi: 10.1007/s10840-012-9672-7. PMID: 22382715.

4. Kuniewic M, Mazur M, Karkowski G, Budnicka K, Przybycień W, Walocha J, Lelakowski J. Tracing 
The Right Phrenic Nerve - A Systematic Review and Meta- Analysis. J Atr Fibrillation. 2020 Oct 13, Issue-3, 1-8.

5. Saitoh Y, Irfan G, Ciconte G, Mugnai G, Sieira J, Di Giovanni G, Baltogiannis G, Conte G, Hünük B, Ströker E, Velagić V, Overeinder I, De Asmundis C, Chierchia GB, Brugada P. Persistence of Phrenic Nerve Palsy Following 28-mm Cryoballoon Ablation: A Four-Year Single Center Experience. Pacing Clin Electrophysiol. 2015 Jul;38(7):807-14. doi: 10.1111/pace.12636. Epub 2015 Apr 27. PMID: 25851416.

6. Aryana A, Singh SM, Kowalski M, Pujara DK, Cohen AI, Singh SK, Aleong RG, Banker RS, Fuenzalida CE, Prager NA, Bowers MR, D'Avila A, O'Neill PG. Acute and Long-Term Outcomes of Catheter Ablation of Atrial Fibrillation Using the Second-Generation Cryoballoon versus Open-Irrigated Radiofrequency: A Multicenter Experience. J Cardiovasc Electrophysiol. 2015 Aug;26(8):832-839. doi: 10.1111/jce.12695. Epub 2015 Jun 4. PMID: 25917655.

7. Okishige K, Aoyagi H, Kawaguchi N, Katoh N, Yamashita M, Nakamura T, Kurabayashi M, Suzuki H, Asano M, Gotoh K, Shimura T, Yamauchi Y, Kanazawa T, Sasano T, Hirao K. Novel method for earlier detection of phrenic nerve injury during cryoballoon applications for electrical isolation of pulmonary veins in patients with atrial fibrillation. Heart Rhythm. 2016 Sep;13(9):1810-6. doi: 10.1016/j.hrthm.2016.05.003. Epub 2016 May 3. PMID: 27154231.

8. Fürnkranz A, Bordignon S, Schmidt B, Perrotta L, Dugo D, De Lazzari M, Schulte-Hahn B, Nowak B, Chun JK. Incidence and characteristics of phrenic nerve palsy following pulmonary vein isolation with the second-generation as compared with the first-generation cryoballoon in 360 consecutive patients. Europace. 2015 Apr;17(4):574-8. doi: 10.1093/europace/euu320. Epub 2015 Jan 6. PMID: 25564551.

9. Andrade JG, Khairy P, Guerra PG, Deyell MW, Rivard L, Macle L, Thibault B, Talajic M, Roy D, Dubuc M. Efficacy and safety of cryoballoon ablation for atrial fibrillation: a systematic review of published studies. Heart Rhythm. 2011 Sep;8(9):1444-51. doi: 10.1016/j.hrthm.2011.03.050. Epub 2011 Mar 30. Erratum in: Heart Rhythm. 2011 Nov;8(11):1828. PMID: 21457789.

10. Martins RP, Hamon D, Césari O, Behaghel A, Behar N, Sellal JM, Daubert JC, Mabo P, Pavin D. Safety and efficacy of a second-generation cryoballoon in the ablation of paroxysmal atrial fibrillation. Heart Rhythm. 2014 Mar;11(3):386-93. doi: 10.1016/j.hrthm.2014.01.002. Epub 2014 Jan 1. PMID: 24389575 .

11. Fürnkranz A, Bordignon S, Dugo D, Perotta L, Gunawardene M, Schulte-Hahn B, Nowak B, Schmidt B, Chun JKR. Improved 1-year clinical success rate of pulmonary vein isolation with the secondgeneration cryoballoon in patients with paroxysmal atrial fibrillation. J Cardiovasc Electrophysiol. 2014 Aug;25(8):840-844. doi: 10.1111/jce.12417. Epub 2014 May 2. PMID: 24654794.

12. Giovanni GD, Wauters K, Chierchia GB, Sieira J, Levinstein M, Conte G, DE Asmundis C, Baltogiannis G, Saitoh Y, Ciconte G, Julia J, Mugnai G, Irfan G, Brugada P. One-year follow-up after single procedure Cryoballoon ablation: a comparison between the first and second generation balloon. J Cardiovasc Electrophysiol. 2014 Aug;25(8):834-839. doi: 10.1111/jce.12409. Epub 2014 Apr 9. PMID: 24641307.

13. Casado-Arroyo R, Chierchia GB, Conte G, Levinstein M, Sieira J, Rodriguez-Mañero M, di Giovanni G, Baltogiannis Y, Wauters K, de Asmundis C, Sarkozy A, Brugada P. Phrenic nerve paralysis during cryoballoon ablation for atrial fibrillation: a comparison between the first- and second-generation balloon. Heart Rhythm. 2013 Sep;10(9):1318-24. doi: 10.1016/j.hrthm.2013.07.005. Epub 2013 Jul 24. PMID: 23891574.

14. Su W, Kowal R, Kowalski M, Metzner A, Svinarich JT, Wheelan K, Wang P. Best practice guide for cryoballoon ablation in atrial fibrillation: The compilation experience of more than 3000 procedures. Heart Rhythm. 2015 Jul;12(7):1658-66. doi: 10.1016/j.hrthm.2015.03.021. Epub 2015 Mar 14. PMID: 25778428.

15. Franceschi F, Dubuc M, Guerra PG, Khairy P. Phrenic nerve monitoring with diaphragmatic electromyography during cryoballoon ablation for atrial fibrillation: the first human application. Heart Rhythm. 2011 Jul;8(7):1068-71. doi: 10.1016/j.hrthm.2011.01.047. Epub 2011 Feb 9. PMID: 21315843.

16. Mondésert B, Andrade JG, Khairy P, Guerra PG, Dyrda K, Macle L, Rivard L, Thibault B, Talajic 
M, Roy D, Dubuc M, Shohoudi A. Clinical experience with a novel electromyographic approach to preventing phrenic nerve injury during cryoballoon ablation in atrial fibrillation. Circ Arrhythm Electrophysiol. 2014 Aug;7(4):605-11. doi: 10.1161/CIRCEP.113.001238. Epub 2014 Jul 13. Erratum in: Circ Arrhythm Electrophysiol. 2014 Oct;7(5):995. Shohoudi, Azadeh [added]. PMID: 25017398.

17. Lakhani M, Saiful F, Parikh V, Goyal N, Bekheit S, Kowalski M. Recordings of diaphragmatic electromyograms during cryoballoon ablation for atrial fibrillation accurately predict phrenic nerve injury. Heart Rhythm. 2014 Mar;11(3):369-74. doi: 10.1016/j.hrthm.2013.11.015. Epub 2013 Nov 16. PMID: 24252287.

18. Moher D, Liberati A, Tetzlaff J, Altman DG, Group P. Preferred reporting items for systematic reviews and meta-analyses: the PRISMA statement. Int J Surg. 2010;8(5):336-41

19. Wells G, Shea B, O'Connell D, Robertson J, Peterson J, Welch V, et al. The Newcastle-Ottawa Scale (NOS) for assessing the quality of nonrandomized studies in meta-analyses Ottawa Health Research Institute. 2013. Available at: http://www.ohri. ca/programs/clinical-epidemiology/oxford.Asp

20. Malmborg H, Lönnerholm S, Blomström-Lundqvist C. Acute and clinical effects of cryoballoon pulmonary vein isolation in patients with symptomatic paroxysmal and persistent atrial fibrillation. Europace. 2008 Nov;10(11):1277-80. doi: 10.1093/europace/eun286. PMID: 18955410.

21. Neumann T, Vogt J, Schumacher B, Dorszewski A, Kuniss M, Neuser H, Kurzidim K, Berkowitsch A, Koller M, Heintze J, Scholz U, Wetzel U, Schneider MA, Horstkotte D, Hamm CW, Pitschner HF. Circumferential pulmonary vein isolation with the cryoballoon technique results from a prospective 3-center study. J Am Coll Cardiol. 2008 Jul 22;52(4):273-8. doi: 10.1016/j.jacc.2008.04.021. PMID: 18634982.

22. Van Belle Y, Janse P, Theuns D, Szili-Torok T, Jordaens L. One year follow-up after cryoballoon isolation of the pulmonary veins in patients with paroxysmal atrial fibrillation. Europace. 2008 Nov;10(11):1271-6. doi: 10.1093/europace/eun218. PMID: 18955409; PMCID: PMC2573029.

23. Chun KR, Schmidt B, Metzner A, Tilz R, Zerm T, Köster I, Fürnkranz A, Koektuerk B, Konstantinidou M, Antz M, Ouyang F, Kuck KH. The 'single big cryoballoon' technique for acute pulmonary vein isolation in patients with paroxysmal atrial fibrillation: a prospective observational single centre study. Eur Heart J. 2009 Mar;30(6):699-709. doi: 10.1093/eurheartj/ehn570. Epub 2008 Dec 24. PMID: 19109353; PMCID: PMC2655313.

24. Linhart M, Bellmann B, Mittmann-Braun E, Schrickel JW, Bitzen A, Andrié R, Yang A, Nickenig G, Lickfett L, Lewalter T. Comparison of cryoballoon and radiofrequency ablation of pulmonary veins in 40 patients with paroxysmal atrial fibrillation: a case-control study. J Cardiovasc Electrophysiol. 2009 Dec;20(12):1343-8. doi: 10.1111/j.1540-8167.2009.01560.x. PMID: 19656254.

25. Kojodjojo P, O’Neill MD, Lim PB, Malcolm-Lawes L, Whinnett ZI, Salukhe TV, Linton NW, Lefroy D, Mason A, Wright I, Peters NS, Kanagaratnam P, Davies DW. Pulmonary venous isolation by antral ablation with a large cryoballoon for treatment of paroxysmal and persistent atrial fibrillation: mediumterm outcomes and non-randomised comparison with pulmonary venous isolation by radiofrequency ablation. Heart. 2010 Sep;96(17):1379-84. doi: 10.1136/hrt.2009.192419. PMID: 20801856; PMCID: PMC2976075.

26. Dorwarth U, Schmidt M, Wankerl M, Krieg J, Straube F, Hoffmann E. Pulmonary vein electrophysiology during cryoballoon ablation as a predictor for procedural success. J Interv Card Electrophysiol. 2011 Dec;32(3):205-11. doi: 10.1007/s10840-011-9585-x. Epub 2011 May 19. PMID: 21594628.

27. Guiot A, Savouré A, Godin B, Anselme F. Collateral nervous damages after cryoballoon pulmonary vein isolation. J Cardiovasc Electrophysiol. 2012 Apr;23(4):346-51. doi: 10.1111/j.1540-8167.2011.02219.x. Epub 2011 Nov 14. PMID: 22081875.

28. Jackson N, Barlow M, Leitch J, Attia J. Treating atrial fibrillation: pulmonary vein isolation with the cryoballoon technique. Heart Lung Circ. 2012 Aug;21(8):427-32. doi: 10.1016/j.hlc.2012.03.123. Epub 2012 May 2. PMID: 22554875.

29. Kühne M, Knecht S, Altmann D, Kawel N, Ammann P, Schaer B, Osswald S, Sticherling C. Phrenic nerve palsy during ablation of atrial fibrillation using a 28-mm cryoballoon catheter: predictors and prevention. J Interv Card Electrophysiol. 2013 Jan;36(1):47-54; discussion 54. doi: 10.1007/s10840-012- 
9740-z. Epub 2012 Oct 23. PMID: 23090778.

30. Ghosh J, Sepahpour A, Chan KH, Singarayar S, McGuire MA. Immediate balloon deflation for prevention of persistent phrenic nerve palsy during pulmonary vein isolation by balloon cryoablation. Heart Rhythm. 2013 May;10(5):646-52. doi: 10.1016/j.hrthm.2013.01.011. Epub 2013 Jan 16. PMID: 23333737.

31. Mugnai G, Chierchia GB, de Asmundis C, Sieira-Moret J, Conte G, Capulzini L, Wauters K, RodriguezMañero M, Di Giovanni G, Baltogiannis G, Ciconte G, Saitoh Y, Juliá J, Brugada P. Comparison of pulmonary vein isolation using cryoballoon versus conventional radiofrequency for paroxysmal atrial fibrillation. Am J Cardiol. 2014 May 1;113(9):1509-13. doi: 10.1016/j.amjcard.2014.01.425. Epub 2014 Feb 12. PMID: 24630388.

32. Vogt J, Heintze J, Gutleben KJ, Muntean B, Horstkotte D, Nölker G. Long-term outcomes after cryoballoon pulmonary vein isolation: results from a prospective study in 605 patients. J Am Coll Cardiol. 2013 Apr 23;61(16):1707-12. doi: 10.1016/j.jacc.2012.09.033. Epub 2012 Nov 28. PMID: 23199518.

33. Ang R, Hunter RJ, Baker V, Richmond L, Dhinoja M, Sporton S, Schilling RJ, Pugliese F, Davies C, Earley M. Pulmonary vein measurements on pre-procedural CT/MR imaging can predict difficult pulmonary vein isolation and phrenic nerve injury during cryoballoon ablation for paroxysmal atrial fibrillation. Int J Cardiol. 2015 Sep 15;195:253-8. doi: 10.1016/j.ijcard.2015.05.089. Epub 2015 May 21. PMID: 26048388.

34. Aryana A, Morkoch S, Bailey S, Lim HW, Sara R, d'Avila A, O'Neill PG. Acute procedural and cryoballoon characteristics from cryoablation of atrial fibrillation using the first- and second-generation cryoballoon: a retrospective comparative study with follow-up outcomes. J Interv Card Electrophysiol. 2014 Nov;41(2):177-86. doi: 10.1007/s10840-014-9942-7. Epub 2014 Sep 17. PMID: 25227868.

35. Aytemir K, Gurses KM, Yalcin MU, Kocyigit D, Dural M, Evranos B, Yorgun H, Ates AH, Sahiner ML, Kaya EB, Oto MA. Safety and efficacy outcomes in patients undergoing pulmonary vein isolation with second-generation cryoballoon+. Europace. 2015 Mar;17(3):379-87. doi: 10.1093/europace/euu273. Epub 2014 Nov 5. PMID: 25376699.

36. Mondesert B, Andrade JG, Khairy P, Guerra PG, Dyrda K, Macle L, Rivard L, Thibault B, Talajic M, Roy D, Dubuc M, Shohoudi A. Clinical experience with a novel electromyographic approach to preventing phrenic nerve injury during cryoballoon ablation in atrial fibrillation. Circ Arrhythm Electrophysiol. 2014 Aug;7(4):605-11. doi: 10.1161/CIRCEP.113.001238. Epub 2014 Jul 13. Erratum in: Circ Arrhythm Electrophysiol. 2014 Oct;7(5):995. Shohoudi, Azadeh [added]. PMID: 25017398.

37. Jourda F, Providencia R, Marijon E, Bouzeman A, Hireche H, Khoueiry Z, Cardin C, Combes N, Combes S, Boveda S, Albenque JP. Contact-force guided radiofrequency vs. second-generation balloon cryotherapy for pulmonary vein isolation in patients with paroxysmal atrial fibrillation-a prospective evaluation. Europace. 2015 Feb;17(2):225-31. doi: 10.1093/europace/euu215. Epub 2014 Sep 3. PMID: 25186456.

38. Metzner A, Rausch P, Lemes C, Reissmann B, Bardyszewski A, Tilz R, Rillig A, Mathew S, Deiss $\mathrm{S}$, Kamioka M, Toennis T, Lin T, Ouyang F, Kuck KH, Wissner E. The incidence of phrenic nerve injury during pulmonary vein isolation using the second-generation $28 \mathrm{~mm}$ cryoballoon. J Cardiovasc Electrophysiol. 2014 May;25(5):466-470. doi: 10.1111/jce.12358. Epub 2014 Jan 30. PMID: 24400647.

39. Greiss H, Berkowitsch A, Wojcik M, Zaltsberg S, Pajitnev D, Deubner N, Akkaya E, Guttler N, Hamm C, Neumann T, Kuniss M. The Impact of Left Atrial Surface Area and the Second Generation Cryoballoon on Clinical Outcome of Atrial Fibrillation Cryoablation. Pacing Clin Electrophysiol. 2015 Jul;38(7):815-24. doi: 10.1111/pace.12637. Epub 2015 May 15. PMID: 25851511.

40. Liu J, Kaufmann J, Kriatselis C, Fleck E, Gerds-Li JH. Second generation of cryoballoons can improve efficiency of cryoablation for atrial fibrillation. Pacing Clin Electrophysiol. 2015 Jan;38(1):129-35. doi: 10.1111/pace.12538. Epub 2014 Dec 12. PMID: 25494851.

41. Luik A, Radzewitz A, Kieser M, Walter M, Bramlage P, Hormann P, Schmidt K, Horn N, BrinkmeierTheofanopoulou M, Kunzmann K, Riexinger T, Schymik G, Merkel M, Schmitt C. Cryoballoon Versus Open Irrigated Radiofrequency Ablation in Patients With Paroxysmal Atrial Fibrillation: The Prospective, Randomized, Controlled, Noninferiority FreezeAF Study. Circulation. 2015 Oct 6;132(14):1311- 
9. doi: 10.1161/CIRCULATIONAHA.115.016871. Epub 2015 Aug 17. PMID: 26283655; PMCID: PMC4590523.

42. Meissner A, Maagh P, Christoph A, Oernek A, Plehn G. ECG-Guided Surveillance Technique in Cryoballoon Ablation for Paroxysmal and Persistent Atrial Fibrillation: A Strategy to Prevent From Phrenic Nerve Palsy. Int J Med Sci. 2016 May 10;13(6):403-11. doi: 10.7150/ijms.14383. PMID: 27279788; PMCID: PMC4893553.

43. Wasserlauf J, Pelchovitz DJ, Rhyner J, Verma N, Bohn M, Li Z, Arora R, Chicos AB, Goldberger JJ, Kim SS, Lin AC, Knight BP, Passman RS. Cryoballoon versus radiofrequency catheter ablation for paroxysmal atrial fibrillation. Pacing Clin Electrophysiol. 2015 Apr;38(4):483-9. doi: 10.1111/pace.12582. Epub 2015 Jan 28. PMID: 25627795.

44. Aryana A, Kowalski M, O'Neill PG, Koo CH, Lim HW, Khan A, Hokanson RB, Bowers MR, Kenigsberg DN, Ellenbogen KA; Cryo-DOSING Investigators. Catheter ablation using the third-generation cryoballoon provides an enhanced ability to assess time to pulmonary vein isolation facilitating the ablation strategy: Short- and long-term results of a multicenter study. Heart Rhythm. 2016 Dec;13(12):23062313. doi: 10.1016/j.hrthm.2016.08.011. Epub 2016 Aug 5. PMID: 27503480.

45. Guhl EN, Siddoway D, Adelstein E, Bazaz R, Mendenhall GS, Nemec J, Saba S, Schwartzman D, Voigt A, Wang NC, Jain SK. Incidence and Predictors of Complications During Cryoballoon Pulmonary Vein Isolation for Atrial Fibrillation. J Am Heart Assoc. 2016 Jul 21;5(7):e003724. doi: 10.1161/JAHA.116.003724. PMID: 27444510; PMCID: PMC5015404.

46. Kardos A, Kis Z, Som Z, Nagy Z, Foldesi C. Two-Year Follow-Up after Contact Force Sensing Radiofrequency Catheter and Second-Generation Cryoballoon Ablation for Paroxysmal Atrial Fibrillation: A Comparative Single Centre Study. Biomed Res Int. 2016;2016:6495753. doi: 10.1155/2016/6495753. Epub 2016 May 22. PMID: 27314032; PMCID: PMC4893449.

47. Mugnai G, de Asmundis C, Velagic V, Hunuk B, Stroker E, Wauters K, Irfan G, Overeinder I, Hacioglu E, Hernandez-Ojeda J, Poelaert J, Verborgh C, Paparella G, Brugada P, Chierchia GB. Phrenic nerve injury during ablation with the second-generation cryoballoon: analysis of the temperature drop behaviour in a large cohort of patients. Europace. 2016 May;18(5):702-9. doi: 10.1093/europace/euv346. Epub 2015 Nov 11. PMID: 26564954.

48. Paylos JM, Morales A, Azcona L, Paradela M, Yague R, Gomez-Guijarro F, Lacal L, Clara Ferrero RN, Rodriguez O. Long-Term Evolution of Patients Treated for Paroxysmal Atrial Fibrillation with First and Second Generation Cryoballoon Catheter Ablation with a Prospective Protocol Guided by Complete Bidirectional Left Atrium-Pulmonary Veins Disconnection after Adenosine as Main Target end Point to achieved. Seven Years Follow-up of Patients with a rough estimation profile of Low ALARMEc Score. A Single Center Report. J Atr Fibrillation. 2016 Apr 30;8(6):1400. doi: 10.4022/jafib.1400. PMID: 27909504; PMCID: PMC5089479.

49. Providencia R, Defaye P, Lambiase PD, Pavin D, Cebron JP, Halimi F, Anselme F, Srinivasan N, Albenque JP, Boveda S. Results from a multicentre comparison of cryoballoon vs. radiofrequency ablation for paroxysmal atrial fibrillation: is cryoablation more reproducible? Europace. 2017 Jan;19(1):48-57. doi: 10.1093/europace/euw080. Epub 2016 Jun 5. PMID: 27267554.

50. Straube F, Hartl S, Dorwarth U, Wankerl M, Bunz B, Ebersberger U, Hoffmann E. Cryoballoon ablation for persistent atrial fibrillation - Large single-center experience. J Cardiol. 2016 Dec;68(6):492-497. doi: 10.1016/j.jjcc.2016.02.007. Epub 2016 Mar 11. PMID: 26976341.

51. Yalin K, Abdin A, Lyan E, Sawan N, Liosis S, Elsner C, Jobs A, Bruggemann B, Koester J, Eitel I, Eitel C, Tilz RR. Safety and efficacy of persistent atrial fibrillation ablation using the second-generation cryoballoon. Clin Res Cardiol. 2018 Jul;107(7):570-577. doi: 10.1007/s00392-018-1219-1. Epub 2018 Feb 28. PMID: 29492703.

52. Miyazaki S, Kajiyama T, Watanabe T, Hada M, Yamao K, Kusa S, Igarashi M, Nakamura H, Hachiya H, Tada H, Hirao K, Iesaka Y. Characteristics of Phrenic Nerve Injury During Pulmonary Vein Isolation Using a 28-mm Second-Generation Cryoballoon and Short Freeze Strategy. J Am Heart Assoc. 2018 Mar 24;7(7):e008249. doi: 10.1161/JAHA.117.008249. PMID: 29574457; PMCID: PMC5907598.

53. Okishige K, Aoyagi H, Shigeta T, Nakamura RA, Nishimura T, Yamauchi Y, Keida T, Sasano T, Hirao 
K. Quick, safe, and effective maneuver to prevent phrenic nerve injury during cryoballoon ablation of atrial fibrillation. J Interv Card Electrophysiol. 2018 Nov;53(2):233-238. doi: 10.1007/s10840-0180379-2. Epub 2018 May 24. PMID: 29797153.

54. Mortsell D, Malmborg H, Lonnerholm S, Jansson V, Blomstrom-Lundqvist C. Acute and long-term efficacy and safety with a single cryoballoon application as compared with the standard dual application strategy: a prospective randomized study using the second-generation cryoballoon for pulmonary vein isolation in patients with symptomatic atrial fibrillation. Europace. 2018 Oct 1;20(10):1598-1605. doi: 10.1093/europace/euy014. PMID: 29420721.

55. Akkaya E, Berkowitsch A, Zaltsberg S, Greiss H, Hamm CW, Sperzel J, Kuniss M, Neumann T. Five-year outcome and predictors of success after second-generation cryoballoon ablation for treatment of symptomatic atrial fibrillation. Int J Cardiol. 2018 Sep 1;266:106-111. doi: 10.1016/j.ijcard.2018.03.069. PMID: 29887425.

56. Su W, Orme GJ, Hoyt R, Baker J, Compton S, Fellows C, Harding J, Svinarich JT, Kowalski M, Piedad B, Kenigsberg D, Seger J, Ahmad ZK, Wang P. Retrospective review of Arctic Front Advance Cryoballoon Ablation: a multicenter examination of second-generation cryoballoon (RADICOOL trial). J Interv Card Electrophysiol. 2018 Apr;51(3):199-204. doi: 10.1007/s10840-018-0335-1. Epub 2018 Feb 24. PMID: 29478173.

57. Molenaar MMD, Timmermans CC, Hesselink T, Scholten MF, Ter Bekke RMA, Luermans JGLM, Brusse-Keizer M, Kraaier K, Ten Haken B, Grandjean JG, Vernooy K, van Opstal JM. Shorter cryoballoon applications times do effect efficacy but result in less phrenic nerve injury: Results of the randomized 123 study. Pacing Clin Electrophysiol. 2019 May;42(5):508-514. doi: 10.1111/pace.13626. Epub 2019 Mar 5. PMID: 30756393; PMCID: PMC6850154.

58. Chikata A, Kato T, Usuda K, Fujita S, Maruyama M, Otowa KI, Takashima SI, Murai H, Usui S, Furusho H, Kaneko S, Takamura M. Coronary sinus catheter placement via left cubital vein for phrenic nerve stimulation during pulmonary vein isolation. Heart Vessels. 2019 Oct;34(10):1710-1716. doi: 10.1007/s00380-019-01402-4. Epub 2019 Apr 10. PMID: 30972550.

59. Chan NY, Choy CC, Yuen HC, Chow HF, Fong HF. Long-term outcomes of cryoballoon pulmonary vein isolation for paroxysmal and persistent atrial fibrillation in Chinese patients. J Interv Card Electrophysiol. 2020 Apr;57(3):425-434. doi: 10.1007/s10840-019-00542-x. Epub 2019 Apr 23. PMID: 31016428.

60. Sano M, Urushida T, Matsukura G, Sakakibara T, Suwa K, Naruse Y, Ohtani H, Saotome M, Maekawa Y. Clinical feasibility of pulmonary vein orifice pacing for the prediction of phrenic nerve injury during cryoballoon ablation of atrial fibrillation. J Cardiovasc Electrophysiol. 2019 Aug;30(8):1200-1206. doi: 10.1111/jce.13962. Epub 2019 May 15. PMID: 31045300.

61. Van Belle Y, Janse P, Rivero-Ayerza MJ, Thornton AS, Jessurun ER, Theuns D, Jordaens L. Pulmonary vein isolation using an occluding cryoballoon for circumferential ablation: feasibility, complications, and short-term outcome. Eur Heart J. 2007 Sep;28(18):2231-7. doi: 10.1093/eurheartj/ehm227. Epub 2007 Jun 14. PMID: 17569680.

62. Stroker E, de Asmundis C, Saitoh Y, Velagić V, Mugnai G, Irfan G, Hünük B, Tanaka K, Belsack D, Buyl R, Brugada P, Chierchia GB. Anatomic predictors of phrenic nerve injury in the setting of pulmonary vein isolation using the 28-mm second-generation cryoballoon. Heart Rhythm. 2016 Feb;13(2):342-51. doi: 10.1016/j.hrthm.2015.10.017. Epub 2015 Oct 13. PMID: 26573972.

63. Whiteman S, Saker E, Courant V, Salandy S, Gielecki J, Zurada A, Loukas M. An Anatomical Review of the Left Atrium. Translational Research in Anatomy . Transl. Res. Anat. 2019, 17, 100052.

64. Cheng X, Hu Q, Zhou C, Liu LQ, Chen T, Liu Z, Tang X. The long-term efficacy of cryoballoon vs irrigated radiofrequency ablation for the treatment of atrial fibrillation: A meta-analysis. Int J Cardiol. 2015 Feb 15;181:297-302. doi: 10.1016/j.ijcard.2014.12.002. Epub 2014 Dec 3. PMID: 25540844.

65. Ciconte G, Baltogiannis G, de Asmundis C, Sieira J, Conte G, Di Giovanni G, Saitoh Y, Irfan G, Mugnai G, Hunuk B, Chierchia GB, Brugada P. Circumferential pulmonary vein isolation as index procedure for persistent atrial fibrillation: a comparison between radiofrequency catheter ablation and second-generation cryoballoon ablation. Europace. 2015 Apr;17(4):559-65. doi: 10.1093/euro- 
pace/euu350. Epub 2015 Jan 12. PMID: 25582875.

66. Heeger CH, Pott A, Sohns C, Rillig A, Kuniss M, Cay, S, Miyazaki S, Aryana A, Jedrzejczyk-Patej E, Aytemir K, Inaba O, Chun JKR, Sommer P, Dahme T, Tilz RR. Phrenic nerve injury during pulmonary vein isolation using the second-generation cryoballoon: characteristics and follow-up - The YETI registry. European Heart Journal . 2019.40 (Supplement_1), 6121.

67. Sacher F, Monahan KH, Thomas SP, Davidson N, Adragao P, Sanders P, Hocini M, Takahashi Y, Rotter M, Rostock T, Hsu LF, Clémenty J, Haïssaguerre M, Ross DL, Packer DL, Jaïs P. Phrenic nerve injury after atrial fibrillation catheter ablation: characterization and outcome in a multicenter study. J Am Coll Cardiol. 2006 Jun 20;47(12):2498-503. doi: 10.1016/j.jacc.2006.02.050. PMID: 16781380.

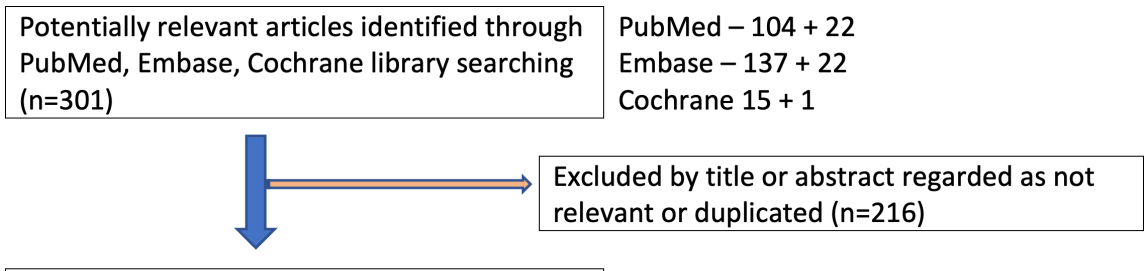

Records kept for further evaluation ( $n=85$ )

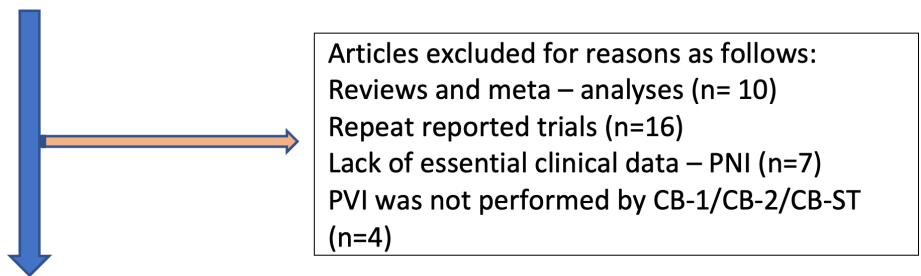

Trials included in meta - analysis ( $n-48)$ PNI registry without duplication: $n-48$ Location of PNI: $n-37$

Intraoperative data of n-PNI (time): $n-8$ Intraoperative data of $n-P N I$ (temp): $n-6$ Follow up information of PNI: $n-37$
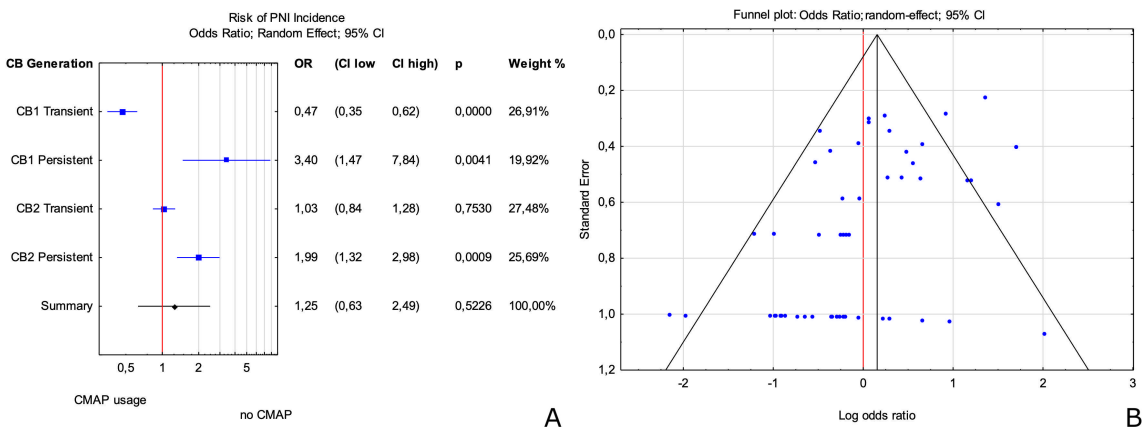

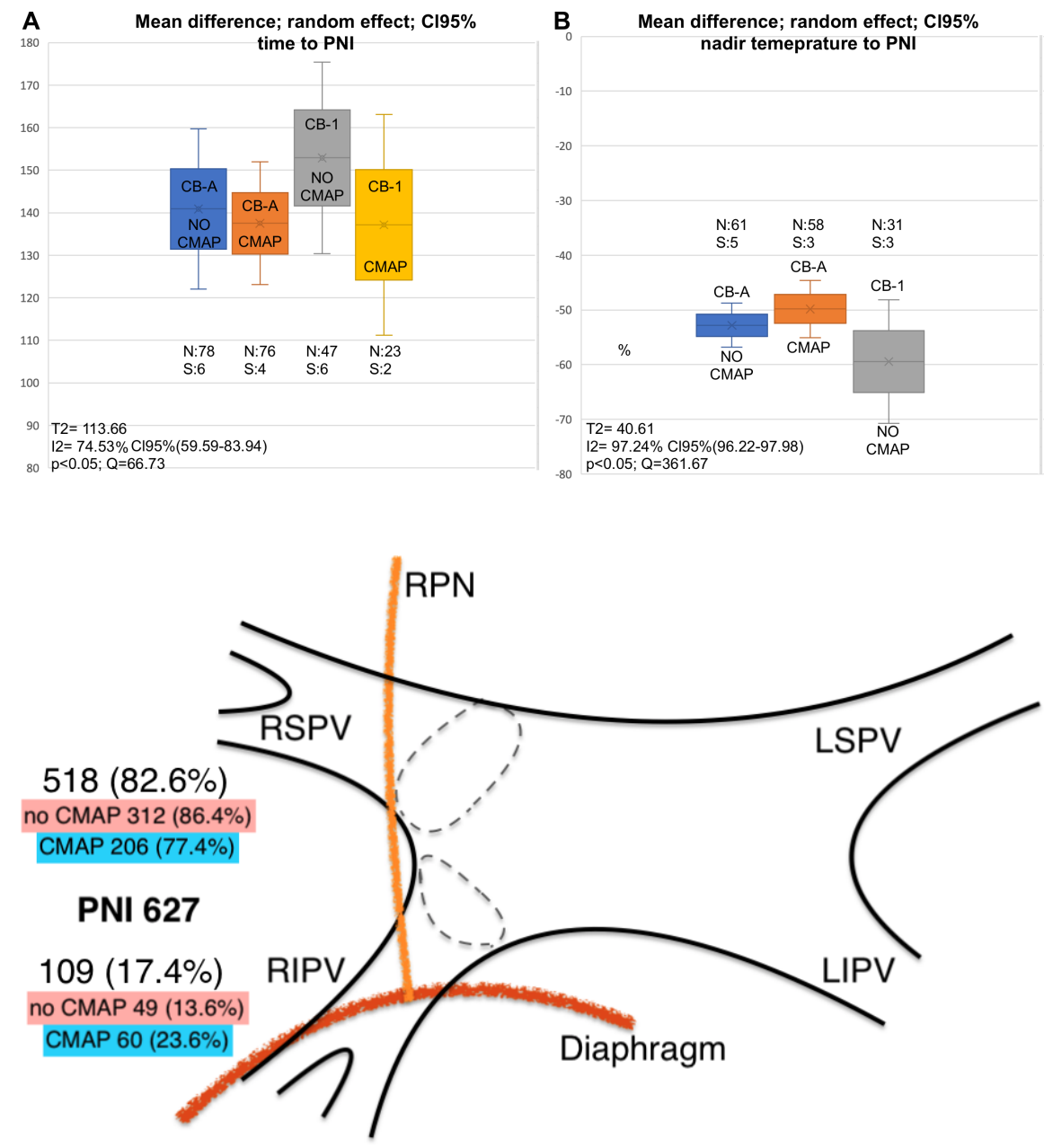


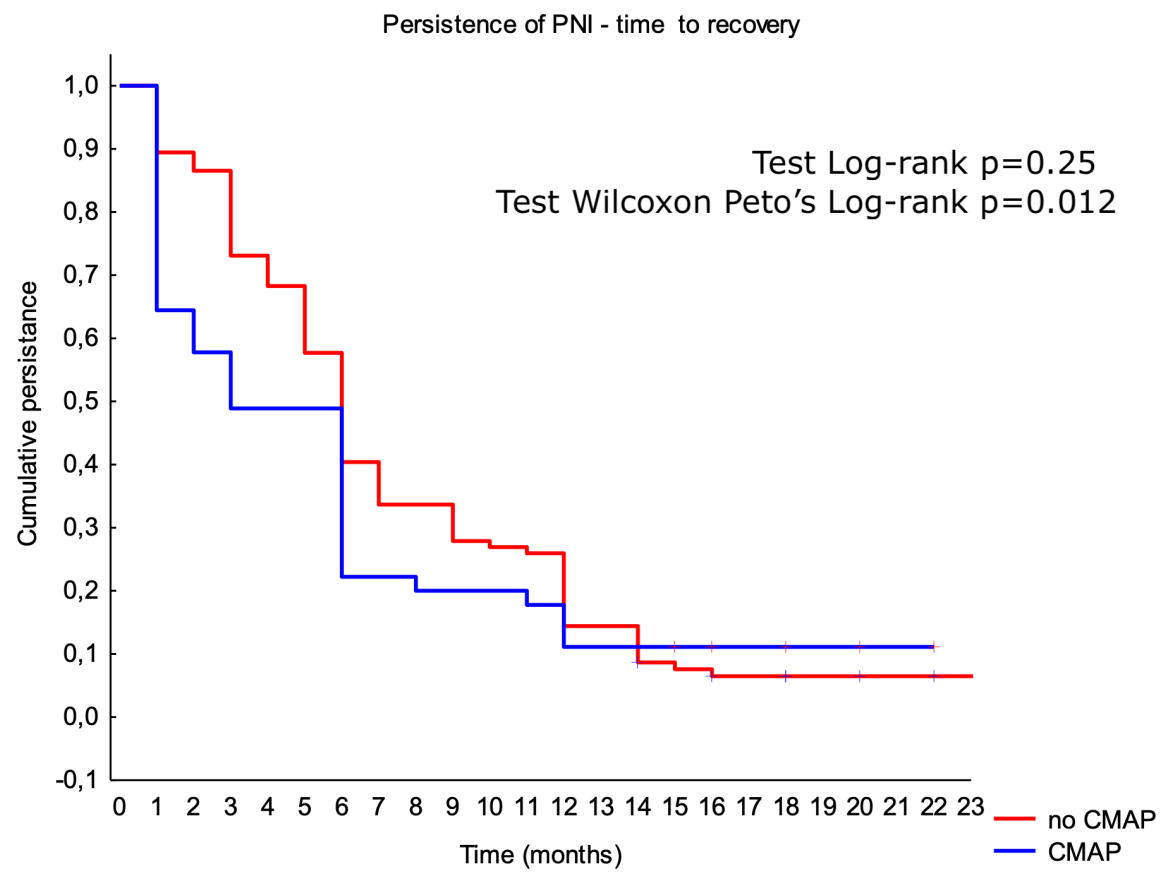

\section{Hosted file}

Tables for CMAP_PNI.docx available at https://authorea.com/users/360103/articles/544860compound-motor-action-potentials-in-transient-and-persistent-phrenic-nerve-injurymetanalysis 